\title{
The role of energy in creating opportunities for income generation in the Indian Himalayas
}

\author{
Annemarije L. Kooijman-van Dijk \\ CSTM University of Twente, Enschede, The Netherlands
}

\section{A R T I C L E I N F O}

Article history:

Received 3 August 2010

Accepted 4 November 2011

Available online 26 November 2011

\section{Keywords:}

Energy

Income

Small enterprise

\begin{abstract}
A B S T R A C T
Although it is clear that there are links between access to modern energy carriers and economic development, the necessary understanding of these links is lacking. Research in literature shows mixed results. This paper studies the mechanisms that link energy supply and impacts on income generation. Empirical data from 264 small scale enterprises in 16 clusters of villages in the Indian Himalayas is analysed. The steps between energy supply and impacts on enterprise are stratified, studying actual energy use of energy services. The analysis shows that for the majority of typical enterprises in rural areas, which are informal enterprises with less than 6 workers, the impacts on incomes are low even though the uptake of electricity in enterprises is high. The key factor influencing impacts on incomes is limitations in access to markets for enterprise products, especially social access. For most small scale rural entrepreneurs the main impacts of energy access are on wellbeing. The findings are discussed to come to policy recommendations in the field of energy supply and complementary fields to achieving positive impacts on rural development.
\end{abstract}

(c) 2011 Elsevier Ltd. All rights reserved.

\section{Introduction}

\subsection{Energy and income generation}

The acknowledgement of the contribution of energy to implementing the Millennium Development Goals following the 2002 World Summit on Sustainable Development (WSSD) in Johannesburg has resparked the attention for energy access on the poverty reduction and economic development agenda (Barnes, 2007; DFID, 2002; IDA, 2005; International Energy Agency, 2002; Modi et al., 2006; UN-Energy, 2005; WSSD, 2002). Of the multiple potential benefits of creating access to modern forms of energy, increasing opportunities for income generation is often assumed to be one of the most important impacts. This is reflected in policies and projects promoting energy with a poverty reduction and economic development objective. The Dutch-German partnership "Energising Development" which has provided access to modern energy services for five million people in developing countries as follow-up to the WSSD, for example takes this stance, stating; "By generating additional income for a community, productive use is probably the most important contributor to poverty alleviation."(Op de Coul et al., 2010).

The impacts of energy supply on income generation are not only relevant from a poverty reduction perspective, but also from the perspective of increasing the economic viability of supplying energy in developing countries (Barnett, 2000; Brew-Hammond,
2010; International Energy Agency, 2002; Kapadia, 2004; World Bank IEG, 2008). If energy is used for income generation, the increased demand and increased ability to pay for energy services can have a positive impact on the economics of energy supply. Many programmes from governments and development agencies are based on these assumed positive linkages between energy supply and opportunities for income generation, looking for winwin situations. This issue is crucial in a context where investors in the energy sector are sought to meet the unmet energy demands and the increasing volumes of those demands worldwide (Barnes, 2007; Barnett, 2000; Birol, 2005; International Energy Agency, 2009). The number of people currently without access to electricity, at 1.4 billion (compared to 1.6 billion one decade ago) shows the size of the challenge to increase the viability of supply. The depth of the challenge is indicated by Lamech and O'Sullivan (2002), who indicate that typical government efforts to keep prices for users low with the objective to increase access in fact may have the opposite effect by reducing the incentives for providers to increase access. In Asia only $10-50 \%$ of the economic costs of rural electrification are generally recovered. Without change in approach, this situation can only be expected to be aggravated in the future as areas that will be covered will be increasingly remote, and the people receiving access will be increasingly poor as these efforts proceed, because the less remote and less poor are generally provided access to infrastructure first (World Bank IEG, 2008). 
Despite the apparent relevance as input for income generation, rural energy projects over the past decades have generally not had the impacts on economic growth and income generation that they were anticipated to provide (Aitken et al., 2008; ESMAP, 2008; Matly, 2003; Meadows, Riley et al., 2003; Schramm, 1993; World Bank IEG, 2008; World Bank OED, 1995). Understanding of the impacts of energy supply on income generation is therefore not only relevant for the improvement of poverty impacts, but also for the improvement of the financial viability of the energy supply itself. Without such understanding, current policy and strategy documents in the field of energy and development are typically based on assumed positive causal relations from energy supply to income generation.

\subsection{Lack of understanding on causal links between energy and income generation}

Critical literature reviews on the topic of energy and income generation (Meadows et al., 2003; Kooijman-van Dijk, 2008) indicate that understanding of the causality chain between energy supply and impacts on income generation is lacking in mainstream literature and policy, as neither macro-economic or micro-economic studies provide detailed and reliable insight into the links. In macro-economic studies the links between energy and economic indicators appear to depend on the scale of analysis and on the specific research country or area. While global macroeconomic studies indicate a definite correlation between commercial energy consumption (usually electricity) and economic growth (Goldemberg, 1996) or broader Human Development Indicators (White, 2002), statistical studies at country or regional levels have proven all possible directions of causality: from energy to GDP, from GDP to energy, bidirectionality or statistically non-existent (Shiu and Lam, 2004). Karanfil (2009) also signifies the limitations of such methodologies in his paper "How many times again will we examine the energy-income nexus using a limited range of traditional econometric tools?".

It is at micro level that a more critical note is added. Research shows consensus on the fact that energy can improve opportunities for income generation but that the evidence is largely anecdotal, and often based on so-called 'best cases'. However, the usefulness of such evidence for the development of new projects or of policy remains limited, as it does not provide information for practical extrapolation of findings outside of the specific cases.

There are only few studies based on empirical evidence that rise above the anecdotal level (Fishbein, 2003; Meadows et al., 2003; Ramani and Heijndermans, 2003). Among the most renowned and influential of these are the ENPOGEN study in China, Indonesia and Sri Lanka (IDS, 2003; Madon, 2003; Massé, 2003; Ramani and Heijndermans, 2003) and the ESMAP study in the Philippines (ESMAP, 2002). These two studies are analysed below, focussing on the causal links between energy supply and enterprise income which is presented positively in both reports.

The ENPOGEN studies performed in Indonesia and Sri Lanka found that incomes in enterprises using electricity were higher than those not using electricity. The found differences are interpreted as a positive impact of the use of electricity (Ramani and Heijndermans, 2003) However, a critical review of the data indicates that although access to electricity has likely contributed to higher incomes, the findings are very specific to the researched area and cannot be generalised. The most positive impact cited in the ENPOGEN studies is a doubling of incomes in enterprises using electricity in the research area in Indonesia in an established cluster of enterprises producing garments and footwear for the international market. It is notable that even in this 'best case', the detailed report presents the finding that not all, but $30 \%$ of entrepreneurs stated that electricity had had a positive impact on income from economic activities. The ENPOGEN study on China (IDS, 2003) states that respondents experienced the possibilities of using electricity for increasing incomes from local income generation to be limited and that the main impact had been reduction of workloads and freeing of time.

The ESMAP study (2002) has the objective to quantify social and financial impacts of electrification. It is calculated that the benefits of electricity per month would be 34 USD in an existing business and 75 USD for a new business, equivalent to approximately one third, respectively, two thirds of monthly income at local average wages. The calculation of these benefits of electricity is based on two assumptions: first that longer opening hours of businesses with access to electricity can be related one-on-one to the use of electricity (rather than for instance to location of the enterprise in evening markets), and secondly that extra opening hours would generate an additional income equivalent to the average wage rate in the area. These assumptions are not supported by the provided background field data. In fact, a different section of the same report states that the total time spent in running a home business is unrelated to the total amount of income from the business.

The above studies show that attributing differences between assets of enterprises to the access to modern energy should not be automatic based on output indicators. Other explanations for the findings are possible. An overriding cause for the general finding that households and enterprises with electricity are generally doing better than those without could be that their starting position is not the same, neither in terms of finance or location. Taking into account the dissemination pattern of electricity or other modern energy carriers would provide a different set of explanations for findings. Modern energy access is not only generally gained earlier by households and enterprises with better financial starting positions and assets, but also in villages with better conditions for enterprise development such as larger concentrations of population and locations along roads. Such attribution issues are insufficiently researched, and are not taken into account in the presentation of research results of studies such as the above mentioned ESMAP and ENPOGEN reports. Further, the causal chain between energy access, energy use and impacts is not studied in sufficient detail to be able to come to strong conclusions for the attribution of impacts.

The summaries and conclusions of the above mentioned reports have been influential in building optimistic connotations of the links between energy supply and income generation activities. As creating energy access has many more benefits than income generation alone, the policies and strategies in this field based on this optimism have not necessarily been inconsistent with meeting broader development goals, but a more realistic and detailed insight could be expected to translate into improvements to increase the development goal of increasing income specifically. Furthermore, such optimistic assumptions may jeopardise energy dissemination projects or their positive impacts on poverty reduction if they are based on assumptions of increasing ability to pay through productive uses of energy.

"Energy is a necessary, but insufficient condition" (Barnett, 2000; Brew-Hammond, 2010) is a widely used phrase in reports and papers that do recognise that impacts of energy supply on income generation are not automatic. Experts provide long lists of which complementary inputs would be beneficial, typically including improvement of energy supply characteristics, skills, access to finance and roads to access markets (Barnett, 2000; Zomers, 2001; Ramani and Heijndermans, 2003; Cabraal et al., 2005; Barnes, 2007; Brew-Hammond, 2010). This paper has the objective to show how such inputs form part of the causal linkages between energy supply and income generation. 


\section{Research in the Indian Himalayas}

This paper presents an assessment of the links between energy supply and income generation based on empirical research. It presents the findings of research regarding the causality chain between supply and impacts of modern energy (including both electricity and fuels such as diesel and LPG) in small scale enterprises based on research in the Indian Himalayas. The findings of this research are presented according to the steps of the causality chain in this section after a short introduction to the methodology (Section 2.1) and the enterprise context (Section 2.2).

\subsection{Methodology}

Empirical research was performed on income generating activities both using and not using modern energy in areas where modern energy supply is available. The study areas consisted of rural areas of three states in the Indian Himalayan range: Himachal Pradesh, Uttarakhand, and West Bengal.

The research included interviews with 264 enterprises in the rural hill areas in the Indian Himalayas and studies of their context in 16 'village clusters' defined as a group of villages with a common market village. Within each cluster, purposive sampling of small enterprises was used on the basis of a list of criteria developed in a pilot study performed by the author in 2004 (Kooijman-van Dijk, 2005). Firstly, selected enterprises belong to sectors that are common in the research areas (such as tailoring, flour milling, carpentry/masonry, blacksmithy, selling prepared food and tea, weaving, metalworks), or sectors which were identified by local policy for rural development as having a high potential for enterprise development such as fruit processing. Secondly, both centrally located enterprises and enterprises in less central locations were included. Other sampling criteria were a spread of enterprises run by males and by females, and enterprises with different scales of operation ranging from casual and informal enterprise to small scale enterprises with 6 or more workers. The enterprises were therefore both tiny and small enterprise as defined by the Government of India (2006) as having an investment level lower than 2.5 million Rs and 50 million Rs, respectively (equivalent at the time of research to approximately 62,500 US\$ and 1.25 million US\$).

Data gathering made use of semi-structured questionnaires for the entrepreneurs and interviews with experts and key informants. The analysis was performed by coding data so that quantitative representation and cross tabulation was possible as basis for qualitative analysis. The concepts belonging to the livelihoods framework are used: positioning the person as central in making decisions about their own livelihoods, and emphasising aspects beyond income alone such as capability and equity (Chambers and Conway, 1992; Solesbury, 2003). The livelihoods framework is adapted to structure information on the various aspects of assets of the entrepreneur and context factors including the influence of energy supply. In the developed approach, the mechanisms of diffusion of modern energy carriers are represented as choices of the entrepreneurs.

In order to analyse the actual impacts of access to energy services on incomes, a distinction is made between new opportunities for income generation or for enterprise growth, and energy services for which there is an alternative from the perspective of the entrepreneur. Impacts therefore depend not only on factors related to functioning of the appliance in the enterprise, but also to the reference case of the entrepreneurs.

Studying the impacts of interventions of any type faces problems of attribution, especially in contexts where many internal and external factors may influence the steps between inputs (in this case energy supply) and impacts. In this study, the impacts are assessed based on the perspectives and historical data provided by the entrepreneurs, and on a comparison between entrepreneurs in situations with different energy access levels, rather than on a comparison with a baseline (as developed for example by Balkema et al. (2010) to assess impacts of renewable energy projects on MDG contributions). A method to study the attribution of impacts is to distinguish between the different steps that form the causal chain. The steps defined are: energy supply and uptake (Section 2.3), uptake of energy appliances (Section 2.4), the actual uses of the appliances and their impacts on the enterprise operation (Section 2.5) and finally, impacts on enterprise and entrepreneur assets. The key role of access to markets for enterprise products and services for the realisation of positive impacts on financial assets is discussed in Section 2.6.

\subsection{The context for enterprises in the Indian Himalayas}

India was selected as country for study, as the Indian context, with its economic growth and its tradition of policy support for small scale enterprises provides a positive context for the development of enterprises, while the widespread occurrence of poverty allows research on poverty impacts. The Himalayas provide a suitable context for information on an electrification process that is ongoing, and where barriers both to modern energy supply and to enterprise development have a strong geographic (rather than political) component. The village clusters in which the research took place were located in rural Himalayan hill areas ranging from half an hour to over four hours travel to the nearest (small) town by car in each of the three states Himachal Pradesh, Uttarakhand and West Bengal. These areas are locally referred to as the lower and mid hills, as opposed to the high hills and mountainous areas. The village clusters were selected so that there is at least some demand for non-subsistence goods (related to demand for enterprise products and services) while at the same time the issue of poverty is also relevant in each village cluster. As an indication, the official 'Below Poverty Line' (BPL) status of the population averages $36 \%$ over the clusters.

The enterprises in these areas are typically small with more than half of the enterprises being run as 'Own Account Enterprises': without hired staff, but operating more than 100 day a year as defined by the Government of India (NSSO, 2002). About half of all enterprises are located in the village cluster centre, with the remainder being spread along roads, in off-road locations outside the cluster centre (mainly within households) and operating without a fixed location.

\subsection{Energy supply and energy uptake}

The first step in the energy chain is that from energy supply to energy uptake. Access to modern energy at household level was relatively high in the research clusters, as a developed energy supply infrastructure was one of the criteria for selection of research locations. Electricity access reached $40-100 \%$ of households per village cluster. Access to kerosene was minimally through the government distribution network. LPG distribution points were present at the central village in each research village cluster. Diesel and petrol are available at tank stations, and like coal and charcoal, are purchased at a distance from the research village clusters. Wood is available in all villages, and is the most common cooking fuel in households.

Within this context, the uptake of electricity in enterprises is high, with 215 of the 264 entrepreneurs having access in their enterprise (including inside the home in the case of home-based enterprises). The uptake of other energy carriers is sector specific, related to for example demand for heat. 
It was found that the access to energy supply is not a matter of infrastructure alone. Access issues differ depending on the characteristics of the energy carrier. Electricity access depends on the available infrastructure at village level, not only for households, but also for enterprises. It was found that electricity connections were only taken if a grid line was made available in the village hamlet in which the enterprise was located. Only for three phase electricity, enterprises invested to acquire a connection. The enterprise at longest distance from the transformer was a one of the largest scale enterprises in the sample: a flour miller located along a road at $400 \mathrm{~m}$ from the transformer. For many entrepreneurs, availability of electricity along roads or in village centres was a reason to choose a location for their enterprises. However, females and people from lower castes in these areas are much less flexible to choose the location of their work, and therefore are also limited also in accessing (higher quality of) electricity supply.

In contrast to electricity, access to fuels (diesel, kerosene, LPG, coal, and charcoal) was found to be less dependent on the physical location of distribution. Here social networks were found to be a key factor in access for the relatively small quantities required by the majority of enterprises, with regular supply being taken care of by friends up to distances of four hours drive. On the other hand, lack of the right social networks reduces access even if supply infrastructure is available locally, as prices and reliability of supply were found to depend to a large extent on relationships between customers and suppliers of fuels, especially for wood and kerosene.

The influence of time on increasing uptake after availability of infrastructure for access was studied by comparing locations with different periods since electrification. The findings indicate that decades after the establishment of energy infrastructure the diffusion of appliances with modern energy demand is still taking place. The uptake of lighting increased only from $60 \%$ to $70 \%$ of enterprises after the first 10 years, while the uptake of appliances for enterprise products and services increased from $27 \%$ to $57 \%$. The diffusion process of electric appliances follows electrification at a pace independent of electrification, but instead depends on the (latent) demand for the energy services which can lead to immediate or much later uptake of appliances.

The quality of energy supply itself also influences impacts after uptake.

For low quality electricity supply, the impacts depend on the appliances used. Enterprise operation often stops during blackouts, and where blackouts or fluctuating voltage causes damage to appliances and products such as in electric sewing and cooling, the costs of low energy supply are high. This leads to reduced uptake and use of electric appliances, and increased risk of those who do. Especially for larger scale enterprises that are dependent on electricity for operation, the impacts of low reliability of supply can only be borne by entrepreneurs with considerable financial flexibility. Alternative electricity supply through diesel backups is only feasible or appropriate for very few enterprises. Further, predictability of blackouts and their duration proved to be highly relevant to enterprise operation, as enterprise operation can often be adapted temporarily. Finally, a high frequency of blackouts or power fluctuations was found to be highly damaging to enterprise operation.

For fuels, low quality of supply leads to diversification of energy carriers as an important strategy for continuity of energy services for those who can afford it. The costs of storage of fuels (for example LPG cylinders) and use of reliable rather than only the lowest cost fuels lead to higher investment and operational costs. Unreliable supply causes inequity between enterprises which can afford this operational strategy and those who have to accept discontinuity of energy services.

\subsection{Uptake of energy appliances}

When energy supply has led to energy uptake, the next step in the causal chain from energy supply to impacts is that of the uptake of energy appliances. For study of impact on income generation, categories of uses of energy were distinguished: uses for direct contribution to production or delivery of enterprise services, lighting, uses for comfort and entertainment (such as electric fan and radio), and uses for communication (telephone, fax, and computer).

Electricity, the most versatile energy carrier, provides a range of energy services in the studied rural enterprises covering all categories as presented in Table 1. The most common type of electricity services is lighting, with 206 of the 264 entrepreneurs having lighting appliances. The energy services for enterprise products and services are sector specific, for instance for tailors electricity provides heating for ironing and light mechanic work for electric sewing, while for millers heavy mechanic work in grinding mills is the core energy service, and for metalworkers welding is a specific energy service. The use of electricity for such enterprise products and services that are directly related to the income generating function of the enterprise occurs in about two thirds of enterprises that have access to electricity, ranging from electric sewing machines to electric flourmills and welding.

Contrasting with electricity, the other energy carriers (diesel, LPG, woodfuel, charcoal, coal, and waterpower) were found to be used nearly exclusively for enterprise products and services. Charcoal, coal, and wood are used for process heat in enterprise products and services. Diesel is used for fuelling engines, or for heating boilers. Kerosene is used mainly for enterprise products and services as a fuel for heating in fruit processing, small restaurants, and sweets production. Occurrence of uses of these other energy carriers outside of providing enterprise products and services, such as kerosene for lighting, or wood for comfort with small open fires in winter, was rare or was considered mainly as back-up.

Overviews of enterprise incomes by electricity use categories and of electricity uses by income groups is informative to point to possible links between uptake of energy and incomes. Tables 2 and 3 below present the findings from two perspectives. In Table 2 the incomes of enterprises are presented for different energy use categories to discuss how incomes may have been affected by energy uptake. Table 3 presents electricity uses for income groups to see how enterprises with different incomes invest in different types of energy appliances.

Table 2 shows a positive relation between electricity use for 'electricity use for enterprise products and services' to income from the enterprise. It also indicates that $39 \%$ of enterprises who have invested in electricity for energy products and services still earn less than 3000 Rs a month from their enterprise, showing that electricity is not the solution to poverty reduction. The numbers for enterprises that do use electricity but not for enterprise products and services show hardly any difference with enterprises not using any electricity at all: respectively, $76 \%$ and $78 \%$ of enterprises within these electricity use categories having an income lower than 3000 Rs, and, respectively, $8 \%$ and 10\% have

Table 1

Categories of use for electricity in the enterprises.

\begin{tabular}{ll}
\hline Categories of use for electricity & Number of enterprises \\
\hline Electricity for enterprise products or services & 147 \\
Electricity for lighting & 206 \\
Electricity for comfort or entertainment & 40 \\
Electricity for communication & 29 \\
\hline
\end{tabular}


Table 2

Incomes from enterprise for electricity use categories.

\begin{tabular}{|c|c|c|c|c|c|c|c|c|c|}
\hline \multirow[b]{2}{*}{ Electricity for enterprise products and services } & \multirow{2}{*}{$\begin{array}{c}\text { Total } \\
148\end{array}$} & \multicolumn{2}{|c|}{ Income $<3000 \mathrm{Rs}$} & \multicolumn{2}{|c|}{ Income $3000-5000 \mathrm{Rs}$} & \multicolumn{2}{|c|}{ Income $>5000 \mathrm{Rs}$} & \multicolumn{2}{|c|}{ Income $>20,000 \mathrm{Rs}$} \\
\hline & & 58 & $39 \%$ & 40 & $27 \%$ & 36 & $24 \%$ & 14 & $9 \%$ \\
\hline Electricity only for light, entertainment, comfort or communication & 67 & 51 & $76 \%$ & 10 & $15 \%$ & 5 & $7 \%$ & 1 & $1 \%$ \\
\hline No electricity at all & 49 & 38 & $78 \%$ & 6 & $12 \%$ & 5 & $10 \%$ & 0 & $0 \%$ \\
\hline Total & 264 & 147 & $56 \%$ & 56 & $21 \%$ & 46 & $17 \%$ & 15 & $6 \%$ \\
\hline
\end{tabular}

Table 3

Electricity uses for income groups.

$\begin{array}{lrll}\begin{array}{l}\text { Estimated income } \\ \text { enterprise owner }\end{array} & \text { Total Electric } & \text { Electricity } & \text { Electricity for No } \\ \text { for } & \text { comfort and electricity } \\ \text { (Rs) } & & \begin{array}{l}\text { enterprise entertainment at all } \\ \text { products } \\ \text { or services }\end{array}\end{array}$

\begin{tabular}{llrrrrrrrr}
\hline$<3000$ & 147 & 104 & $71 \%$ & 58 & $39 \%$ & 18 & $12 \%$ & 38 & $26 \%$ \\
$3000-5000$ & 56 & 47 & $84 \%$ & 40 & $71 \%$ & 11 & $20 \%$ & 6 & $11 \%$ \\
$>5000$ & 46 & 40 & $87 \%$ & 36 & $78 \%$ & 8 & $17 \%$ & 5 & $11 \%$ \\
$>20,000$ & 15 & 15 & $100 \%$ & 14 & $93 \%$ & 3 & $20 \%$ & 0 & $0 \%$ \\
Totals & 264 & 206 & $78 \%$ & 148 & $56 \%$ & 40 & $15 \%$ & 49 & $19 \%$ \\
\hline
\end{tabular}

an income higher than 5000 Rs from an enterprise. These findings can be interpreted in two ways: impacts of electricity for lighting, entertainment, etc. on income are small compared to impacts of electricity for increased production of enterprise products or services, or entrepreneurs with low income from their enterprise tend not to invest in appliances for enterprise products and services, while they do invest in appliances for lighting, comfort etc.

Table 3 shows that the most notable divide in uptake of electric appliances occurs between the lowest income enterprises and the other enterprises in the category enterprise products and services. The differences between the lowest income and other enterprises in uptake of other use categories are much smaller. Therefore both explanations may be valid: such correlation overviews are insufficient basis to provide evidence or understanding of the actual direction of causality: whether energy uptake leads income, or whether enterprises with higher income tend to invest more in energy appliances, or both simultaneously.

Although use of loans could in principle allow all income groups to invest in productive means to increase income generation, this study found limited interest in taking loans and large differences correlating to income groups. Only a small group of entrepreneurs with the highest initial assets, who owned the largest enterprises in the sample, did value loans for enterprise investments such as for modern energy appliances. The other, more typical entrepreneurs in the rural areas, generally expected they would not be able to pay back the loan from increased enterprise profits, The high accessibility of loans through microfinance or rural banks therefore had low impacts on energy investments for all but the most wealthy entrepreneurs, who also have social networks and human skills to access new and larger markets.

This study found that the total number of new enterprise activities (defined as new to the area) related to modern energy access was low. For electricity, such services are metalworks (welding, cutting steel) for cars or building construction and for tyre repair. These enterprise sectors form less than $1 \%$ of enterprises in the studied rural areas (and 5\% of the studied enterprises due to purposive sampling), and are found in villages with relatively high incomes and at locations along important roads. For the common enterprise sector milling, access to grid electricity created new opportunities for enterprise establishment depending on the local perception of appropriateness of alternatives. The acceptability of diesel or direct shaft power from traditional watermills was found to differ in time and between states depending on the comparative pricing between diesel and electricity, reliability of supply of electricity, diesel or water, and level of competition for the local market.

When a modern energy service has alternative carriers for a similar energy service, the changes or differences form the impacts. The changes can be economic for example through reducing costs or increasing production efficiency, or they can be for wellbeing for example through improving comfort or reducing drudgery. An exemplary energy service in which electric appliances form an alternative to traditional forms of production is electric or manual or pedal sewing. The use of these different machines does not essentially alter enterprise products. Of the 60 tailors interviewed, 19 have electric sewing machines, of whom 18 also still have and use manual (including pedal driven) sewing machines. There are also alternatives to investment in modern energy appliances: carpenters were found to borrow or rent electric machines from other carpenters, or buy readymade parts. The use of telephones in telephone shops is a common use of modern energy which does not require access at enterprise location. For this energy service, initial access within a community is more relevant for impacts than the coverage of access to all households or enterprises.

\subsection{Use of energy appliances and impact on enterprise operation}

The actual use of the appliance is a step in the causal chain from energy supply to impacts that is understudied, although it is evident that the frequency and duration of use of the appliance, and the role in enterprise operation as a whole are crucial to the realisation of any potential impacts. The frequency of use and the role in enterprise operation define potential impacts on volumes of production, costs, price developments of products or services, sales/numbers of customers, numbers of staff and profit margins, which eventually form the components of the final impacts on income and employment. The role of energy services provided by modern energy appliances indicates the relevance for the functioning of the enterprise. In the fruit processing sector, electric appliances were used mainly for crushing fruit (heavy mechanical work), but in all enterprises in this sector peeling and mixing was done manually. The electric appliances therefore facilitate operation, but most enterprises in this sector could continue operation without electricity. In the sector tailoring, the highest intensity electricity use (highest frequency and duration and electricity demand) was for ironing, which is not core to the enterprise service. The volume of the electricity demand is therefore not an indicator for the relevance for enterprise operation. For the flour milling sector, the situation is completely different. Here enterprise operation is completely based on energy supply: if not from electricity, then from diesel or waterpower.

The frequency and duration of use is studied in more depth below in two cases: lighting and sewing. The case of lighting illustrates the impacts of increased comfort and opportunities to 
increase working hours, the case of sewing shows impacts of increased efficiency.

Firstly, the case of electric lighting. Considering the improved opportunities to work in the evenings, what are the actual uses of light for this purpose? More than half of the entrepreneurs who have electricity indicated that they do (sometimes) work in the evening, while for entrepreneurs without grid electricity this is one in six. This provides a picture of positive impacts of electricity on enterprise operation. Of the 55 entrepreneurs who stated using electricity to work in the evenings or at night, for half of this group this occurs regularly. For six entrepreneurs, most work takes place in the evening or early morning, and therefore lighting is crucial for these activities, providing the opportunity to establish an enterprise next to other obligations (labour on the tea estate, farming, office jobs), or for the bakery, to produce fresh products before morning. For many entrepreneurs, evening work is not structural, being concentrated in the peak season which is typically a few weeks (22 entrepreneurs), and/or irregular over the year, increasing the flexibility of working hours (26 entrepreneurs).

Although the above enterprises do use electric lighting to increase or change working hours, the impacts of this use on income depends on the sector. For small restaurants and sweet shops, increasing opening hours has a direct impact on ability to serve a larger number of customers and thereby increasing turnover and income. For producing enterprises increasing working hours is functional in increasing production volumes, but not in reaching additional customers which define impacts on income. In service sectors it is difficult to assess in how far increasing opening hours or improved quality of light shifts customers in time or between enterprises, and in how far local turnover is influenced.

Another perspective on the issue of impacts is that of the group of entrepreneurs who do not work in the evenings. Of this group, only $20 \%$ indicate that they would (sometimes) work in the evenings if they did have electricity. 34\% indicate that they would not work because there is not enough work, and $28 \%$ indicate no need or priority even if there is enough work, $13 \%$ cannot work at night because they would have to travel home in the dark. There is also a seasonal motivation not to extend working hours. During three months in winter, a strong factor limiting evening work is the cold. With badly insulated buildings and no heating, both entrepreneurs and potential customers go to bed early to keep warm. This leads to the conclusion that in the large majority of cases, energy access is not the first limiting factor in its use.

The above shows that electric lighting cannot have impacts on income through extending working hours for all enterprises. Firstly, there must be sufficient market demand to justify working in evenings, and secondly, there may be structural barriers to extending working hours independent of lighting or customer demand such as location choice or time limitations of staff. It is especially notable that in the larger enterprises in the sample the flexibility to work in the evenings was reduced compared to smaller enterprises due to formalised worker-owner relationships.

A different potential impact of lighting is the possibility to perform high precision work, such as prevalent in tailoring, weaving, and electric repairs. The use of lighting for such work was found to be sector specific: while none of the 15 weaving enterprises (including the more formalised enterprises with employees) use electricity for lighting during the day, only six of the 60 tailors stated regular use of electric lighting during the day and two tailors during days in the winter, while all five entrepreneurs doing electric repairs use electric light during the day.

The second case to illustrate the impacts of modern energy through studying actual use of appliances is that of electric sewing. Electric sewing can contribute to improved efficiency of enterprise operation by reducing the time needed per produced product. Products are not only comparable with and without modern energy use, but also to a large extent between enterprises. The salwar kameez (a ladies' suit consisting of a tunic and trousers) was taken as the standard reference product. For skilled tailors, it would be possible to make a suit in $1-2 \mathrm{~h}(0.5-1$ suit per hour).

It appears that the efficiency of operation has not increased due to electric sewing machines, as the number of suits made per working hour on an average day per staff member is 0.18 in enterprises using electric sewing machines and 0.17 in those without. Instead, workers in both tailoring enterprises with and without electric sewing machines spend much of their day waiting for customers.

This lack of relation with efficiency is remarkable especially as more entrepreneurs with electric sewing machines have staff and could therefore be expected to pay more attention to efficiency of staff time. Two possible explanation for the lack of efficiency of staff hours in larger enterprises are firstly that staff is commonly paid depending on production independent of time spent, and secondly that larger enterprises tend to have more apprentices who have low to no salaries, and therefore efficiency is only relevant when the ability to meet customer demand is approached. In such times, it is typically the owner of the tailor enterprise who uses the electric sewing machine, rather than staff.

In most of the enterprises with electric sewing machines the bulk of work is still performed on pedal or manual sewing machines. Electric sewing machines are often only used by tailors in the case of urgent customer demand, and for simple work where the time-saving effect is the largest, while for more complicated work or in times of low customer demand, manual or pedal sewing machines are used. Tailors who use electric sewing machines regularly stated that the main impact was that they could go home earlier.

The highest number of suits made per staff member on an average working day was four. This number was reached in one enterprise with electric sewing machines in a seven hours working day, and in two enterprises without electric sewing machines with working days of 10-11 h. Calculated per working hour, these tailors make, respectively, 0.6 and 0.4 suits per hour, amounting to three, respectively, two times more than the average, and approaching the maximum. This indicates that electric sewing machines have an impact but only as long as demand is high enough.

The case of electric sewing therefore, in line with the case of electric lighting, indicates that even when there is electricity uptake and uptake of appliances, there are important barriers to achieving actual impact on income generation, a key factor in this being the market for enterprise products and services.

\subsection{Impacts depend on access to markets for enterprise products and services}

An in-depth study of the markets targeted by the rural entrepreneurs showed that nearly all of the studied 264 enterprises target the local market, and that nearby towns and distant markets play any role only for a small minority. 226 enterprises target only the local market in the village cluster. 53 target both the local market and customers in a small surrounding area. Only 10 have customers in nearby towns, and 35 have distant markets, which can even be outside of the state.

For enterprises targeting the distant market, electric appliances are essential, even in artisanal core production processes which do not require electricity such as traditional manual weaving. Energy services such as for communication and ensuring and monitoring of product standards serve to meet the specific 
demands typically set by such distant markets: higher demands on product and packaging quality, reliability of product quality, and larger scales of production.

For those enterprises targeting local markets, it can be seen that the opportunities to benefit from having electric appliances depends on the income levels in the village in which the enterprise is located and surrounding villages. Especially for furniture and buildings, the demand for quantity and quality of products had pronounced differences related to village levels of wealth. Where carpenters or metalworkers were able to sell more and higher quality products such as beds, dining tables and chairs, cupboards or metal staircases, and shutters, in that case electric appliances played an important role in producing products at higher standards of finishing, and in obtaining production volumes with reduced drudgery for staff. Electric appliances alone are insufficient to reach the higher levels of product quality related to developing market demands: skills of staff were found to be very important. Also for tailoring, demands on products increase with higher levels of income, and it was found that high levels of skills to meet such demands are essential, which could not be compensated for by use of electric appliances. In many enterprises with high skilled staff, the entrepreneur and such staff were not locals, but had developed skills elsewhere, and had come to the villages to find a market. Where entrepreneurs from outside introduced new energy services in competition with traditional production, the availability of electricity had not had positive impacts for opportunities for local entrepreneurs, who typically were less skilled in the production of such new products.

One sector in which the opportunities to develop enterprises are hardly dependent on location or on village income levels is that of flour milling. With the extension of electricity grids into more remote villages, new flourmills are established for the processing of local grains for private consumption by the customers. In this case, the availability of electricity does increase the opportunity to establish enterprises. The impacts on incomes for all flour millers targeting local markets were found to be decreasing with the increasing number of flourmills: saturation of the market for processing grains led to a trend of reduction of number of staff and of working hours per enterprise to the current situation where milling is mainly an additional income-generating activity performed by women and elderly a few hours a day.

Such saturation of local markets is typical for all enterprises targeting only the local markets. For all enterprise sectors, the key elements to realise potential impacts of modern energy services on incomes are therefore social skills and networks to access new markets and business and technical skills to innovate products. Without such skills and networks, the impacts of modern energy services remain largely in the domain of comfort and flexibility of operation, with only small or no positive impacts on income generation for the typical rural entrepreneurs. If skills and networks to markets for the products of rural enterprises do not develop, electricity will not lead a transformation of rural society out of poverty, but rather the opportunities and impacts follow after an increase in wealth.

\section{Discussion of implications for energy projects, energy policy and complementary policy}

This research through its level of detail and focus on mechanisms rather than outcomes is able to indicate implications for policy for energy and rural development. It shows that impacts of rural energy supply on poverty reduction in terms of income generation are small for the typical rural entrepreneur who owns a small scale enterprise targeting the local market.
The discussion below reflects on the key implications of the findings from this study for policy and projects both in the field of energy supply and complementary fields to support the income generation and rural development impacts of energy supply.

The first step in the chain of impacts is that of energy supply. Many of the findings regarding energy supply and access to that energy supply can be extended beyond the research context of the Indian Himalayas. Reliability and predictability of supply, both for fuels and for electricity, are crucial for impacts on income, especially for enterprises that depend on modern energy services for operation. This requires a different approach and awareness activities compared to energy access for households.

Income generation is desirable to increase the ability to pay for energy services, and to contribute to rural development. This study found that for the typical tiny enterprises with local markets in the research areas, the impacts of energy on incomes generally small, and secondary to wellbeing impacts. Only in specific sectors such as milling, the number of enterprises in rural areas that benefit from increased access to modern energy is relatively large, but the positive impacts are limited by saturation of local markets. It is mainly enterprises that access markets outside the local vicinity for which modern energy use has a large impact on income generated. This is valid both for energy services for the main enterprise production process and for supporting energy services such as for communication.

In this research it is shown that the impacts of energy are strongly related to markets for enterprise products and services. The limited impacts on incomes in the Indian Himalayas follow from the limited access of local entrepreneurs to distant markets.

Whether the impacts on income generation in other areas and countries are very different therefore depends on the market infrastructure for local rural enterprises. It is clear however, that the entrepreneurs in the Indian Himalayas are not unique. Studies performed in a range of other countries (Bolivia, Tanzania and Vietnam; Kooijman-van Dijk and Clancy, 2010) and South Africa (Meadows et al., 2003) find that the limited social and financial assets of entrepreneurs limit their benefits from access to energy. In the field of microfinance empirical studies have also shown that outreach to the poor and impacts on poverty reduction are low or lacking in a range of countries (Hermes and Lensink, 2011; Shaw, 2004).

Complementary policy next to energy supply is a condition for impacts to take effect on income generation. The finding that providing access to (micro)finance, may not be the key complementary input is contrary to mainstream ideas such as reflected in the recent methodology written for the purpose of maximising productive uses of electricity in rural areas (ESMAP, 2008).

Instead, the key complementary policy identified in this study for the poor and their tiny enterprises to benefit from energy supply, is the establishment of sustainable links with the market for enterprise products. The stimulation of access to markets should focus on social rather than (only) physical access, as the social distance is at least as inhibitive as the physical distance. Stimulation of market access would build upon business development initiatives that may be combined with electrification programmes to enhance energy demand such as promoted by ESMAP (ESMAP, 2008) and promising examples such as the AHREC work in Nepal (Bastakoti, 2003). However, the findings of this study emphasises that for sustainability of impacts, institution building would need to support in all phases of enterprise development, not only initial phases of identification of ideas for products, and training for basic entrepreneurial skills, but especially continuous market information and training to adapt products to the demand of distant markets.

Complementary policy is not only necessary to support potential positive impacts, but also to reduce the negative impacts that 
occur without such policies. As people with highest social assets (often the most wealthy) and highest mobility are most capable of putting the potential benefits of modern energy to use in increasing incomes, inequity between groups in society increase, typically reducing rather than increasing income generation opportunities for the disadvantaged groups. Reflection on rural development strategies is necessary to reduce barriers for local typical rather than exceptional entrepreneurs, and to increase employment outside of self employment. Approaches may include social mobility projects, training for empowerment in combination with the establishment of buildings or physical market places.

Finally, a comment on the above discussion is made taking the perspective of the typical rural entrepreneurs. The assessment of success of projects and policy for impacts should not focus on income generation alone, as the impacts of energy access on wellbeing are highly appreciated and more easily and widely achieved than impacts on income, also by the poor.

\section{References}

Aitken, R., Kruger, W., Banks, D., Schaeffler, J., 2008. Renewable Energy Access for Productive Use.

Balkema, A.J., Dijk, S. van, Heijnen, S., Verbong, G.P.J., Romijn, H.A. \& Huntjens, E. 2010. An impact assessment methodology for small scale renewable energy projects in developing countries funded under Dutch policies defined to contribute to the millennium development goals. In: Proceedings of the Berlin Conference on the Human Dimensions of Global Environmental Change, Environmental Policy Research Centre (FFU), Berlin, 8-9 October, 2010.

Barnes, D.F., 2007. The Challenge of Rural Electrification. The Challenge of Rural Electrification. Strategies for Developing Countries, Resources for the Future, Washington.

Barnett, A., 2000. Energy and the fight Against Poverty. ISS.

Bastakoti, B.P., 2003. Rural electrification and efforts to create enterprises for the effective use of power. Applied Energy 76, 145-155.

Birol, F., 2005. The investment implications of global energy trends. Oxford Review of Economic Policy 21, 145-153.

Brew-Hammond, A., 2010. Energy access in Africa: challenges ahead. Energy Policy 38, 2291-2301.

Cabraal, A.R., Barnes, D.F., et al., 2005. Productive uses of energy for rural development. Annual Review of Environmental Resources 30, 117-144.

Chambers, R., Conway, G.R., 1992. Sustainable Rural Livelihoods: Practical Concepts for the 21st Century Brighton. Institute of Development Studies.

DFID, 2002. Energy for the Poor, underpinning the Millennium Development Goals: Department For International Development, UK.

ESMAP, 2002. Rural Electrification and Development in the Philippines: Measuring the Social and Economic Benefits. The World Bank, Washington DC.

ESMAP, 2008. Maximising the Productive Uses of Electricity to Increase the Impact of Rural Electrification Programs. The World Bank, Washington, DC.

Fishbein, R., 2003. Survey of Productive Uses of Electricity in Rural Areas.

Goldemberg, J., 1996. Energy, Environment and Development. Earthscan Publications, London.

Government of India, 2006 The Micro, Small and Medium Enterprise Development Act.

Hermes, N., Lensink, R., 2011. Microfinance: its impact, outreach, and sustainability. World Development 39 (6), 875-881.

IDA, 2005. Energy Services for Poverty Reduction and Economic Growth. Retrieved from: 〈http://siteresources.worldbank.org/IDA/Resources/IDA-Energy.pdf $\rangle$.
IDS, 2003. A Review of the Evidence and Case Studies in Rural China. ENPOGEN The World Bank, ASTAE, Washington, DC

International Energy Agency, 2002. World Energy Outlook 2002. IEA/OECD, Paris. International Energy Agency, 2009. World Energy Outlook 2009. OECD/IEA, Paris Kapadia, K., 2004. Productive Uses of Renewable Energy: A Review of Four BankGEF Projects.

Karanfil, F., 2009. How many times again will we examine the energy-income nexus using a limited range of traditional econometric tools? Energy Policy 37, 1191-1194.

Kooijman-van Dijk, A.L., 2005. Energy choices in SME's in rural areas. Paper Presented at the UNDP Expert Meeting on Productive Uses of Renewable Energy, 9-11 May, Bangkok.

Kooijman-van Dijk, A.L., 2008. The Power to Produce: the Role of Energy in Poverty Reduction through Small Scale Enterprises in the Indian Himalayas, Ph.D. Thesis, University of Twente, Enschede.

Kooijman-van Dijk, A.L., Clancy, J., 2010. Impacts of electricity access to rura enterprises in Bolivia, Tanzania and Vietnam. Energy for Sustainable Development 14 (1), 14-31.

Lamech, R., O’Sullivan, K., 2002. Energy. In: Klugman, J. (Ed.), A Sourcebook for Poverty Reduction Strategies. , World Bank, Washington DC (Chapter 21).

Madon, R., 2003. Energy, Poverty, and Gender: Impacts of Rural Electrification on Poverty and Gender in Indonesia Volume 1: Facts, Analysis, and Recommendations. ENPOGEN, MARGE France for The World Bank, ASTAE, Washington, DC.

Massé, R., 2003. Energy, Poverty and Gender: Impacts of Rural Electrification on Poverty and Gender in Sri Lanka. ENPOGEN, MARGE, France for The World Bank, ASTAE, Washington, DC.

Matly, M., 2003. Rural Electrification in Indonesia and Sri Lanka: from Social Analysis to Reform of the Power Sector. ENPOGEN, MARGE, France for The World Bank, ASTAE, Washington, DC.

Meadows, K., Riley, C., et al., 2003. Modern Energy: Impacts on Micro-enterprises, A literature Review into the Linkages between Modern Energy and MicroEnterprises. Department for International Development, UK.

Modi, V., McDade, S., Lallement, D., Saghir, J., 2006. Energy Services for the Millennium Development Goals. Energy Sector Managament Assistance Programme. United Nations Development Programme, UN Millennium Project, and World Bank, New York.

NSSO, 2002. Unorganised Manufacturing Sector in India 2000-2001, characteristics of enterprise NSS 56th round (July 2000-June 2001). NSSO.

Op de Coul, M., Huntjens, E. (Eds.), 2010. GTZ and NL Agency, Eschborn

Ramani, K.V., Heijndermans, E., 2003. Energy, Poverty and Gender: A Synthesis ENPOGEN, The World Bank, ASTAE, Washington, DC.

Schramm, G., 1993. Rural electrification in LDCs as a tool for economic development: facts and fiction. OPEC Review 17, 501-517.

Shaw, J., 2004. Microenterprise Occupation and Poverty Reduction in Microfinance Programs: Evidence from Sri Lanka. World Development 32, 1247-1264.

Shiu, A., Lam, P.L., 2004. Electricity consumption and economic growth in China. Energy Policy 32, 47-54.

Solesbury, W., 2003. Sustainable Livelihoods; A Case Study of the Evolution of DFID Policy. ODI

UN-Energy, 2005. The Energy Challenge for Achieving the Millennium Development Goals (Brochure), United Nations.

White, R., 2002. GEF-FAO Workshop on Productive Uses of Renewable Energy: Experience, Strategies, and Project Development. USAID/GEF, Rome.

World Bank IEG, 2008. The Welfare Impact of Rural Electrification: A Reassessment of the Costs and Benefits. The World Bank, Washington, DC.

World Bank OED, 1995. Rural Electrification: A Hard Look at Costs and Benefits OED Precis, p. 90

WSSD, 2002. Chairperson's summary of the partnership plenary discussion on water and sanitation, energy, health, agriculture and biodiversity (WEHAB), World Summit on Sustainable Development Johannesburg, pp. 1-14.

Zomers, A., 2001. Rural electrification, Utilities' chafe or challenge. Ph.D. Thesis, University of Twente, Enschede. 